\title{
Adeno-associated virus (AAV)-based gene therapy for glioblastoma
}

\author{
Xin Xu ${ }^{1 *+}$, Wenli Chen ${ }^{2 \dagger}$, Wenjun Zhu ${ }^{3+}$, Jing Chen ${ }^{1}$, Bin Ma', Jianxia Ding ${ }^{1}$, Zaichuan Wang ${ }^{5}$, Yifei Li ${ }^{5}$, \\ Yeming Wang ${ }^{4^{*}}$ (I) and Xiaochun Zhang ${ }^{5,6^{*}}$
}

\begin{abstract}
Glioblastoma (GBM) is the most common and malignant Grade IV primary craniocerebral tumor caused by glial cell carcinogenesis with an extremely poor median survival of 12-18 months. The current standard treatments for GBM, including surgical resection followed by chemotherapy and radiotherapy, fail to substantially prolong survival outcomes. Adeno-associated virus (AAV)-mediated gene therapy has recently attracted considerable interest because of its relatively low cytotoxicity, poor immunogenicity, broad tissue tropism, and long-term stable transgene expression. Furthermore, a range of gene therapy trials using AAV as vehicles are being investigated to thwart deadly GBM in mice models. At present, AAV is delivered to the brain by local injection, intracerebroventricular (ICV) injection, or systematic injection to treat experimental GBM mice model. In this review, we summarized the experimental trials of AAV-based gene therapy as GBM treatment and compared the advantages and disadvantages of different AAV injection approaches. We systematically introduced the prospect of the systematic injection of AAV as an approach for AAV-based gene therapy for GBM.
\end{abstract}

Keywords: AAV, Glioblastoma, Gene therapy, Systemic injection, Local injection, Intracerebroventricular injection

\section{Introduction}

Glioblastoma (GBM) is a tumor located in the central nervous system (CNS) that forms in the supportive tissue of the brain [1]. Human GBM is highly invasive and spreads rapidly to nearby healthy brain tissues before symptoms occur [2]. GBM has been reported to be the most lethal intracranial tumor because of its high resistance to conventional radiotherapy and chemotherapy [3]. Despite advances in surgery, the complex genetic heterogeneity and insidious infiltration of GBM cells result

\footnotetext{
*Correspondence: xinxin_8912@hotmail.com;wym7938@163.com; ceiq@sina.com

${ }^{\dagger}$ Xin Xu, Wenli Chen and Wenjun Zhu contributed equally to this work

${ }^{1}$ School of Medicine, Jiangsu University, Zhenjiang 212013, Jiangsu, China

${ }^{4}$ Department of Hepatobiliary Surgery, The Second People's Hospital of Lianyungang, Lianyungang 222006, Jiangsu, China

${ }^{6}$ Department of Oncology, Yangzhou Traditional Chinese Medical Hospital, Yangzhou 225600, Jiangsu, China

Full list of author information is available at the end of the article
}

in almost inevitable recurrence with less than 5\% 5-year survival rate [4]. Another major obstacle in GBM treatment is the blood-brain barrier (BBB), which limits the diffusion of most small-molecule therapeutic agents and all large molecules into the brain parenchyma and blocks the drug treatment of GBM [5]. Thus, developing effective therapeutic strategies that provide improved clinical therapeutic efficiency and increased survival rate among patients with GBM is urgently needed.

Gene therapy refers to the introduction of foreign genes into target cells to correct or compensate for diseases caused by defective or abnormal genes to achieve therapeutic purposes; this strategy is promising for many diseases, including cancer, neurodegenerative, and cardiovascular diseases [6, 7]. More than 2000 clinical trials of gene therapy have been conducted, and most of the vectors have been proven effective and safe [8]. Current studies indicate that approximately $64 \%$ of the clinical trials of gene therapy were conducted to treat cancer diseases, and the most common strategy is the delivery of

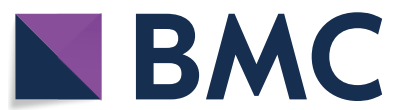

c) The Author(s) 2021. This article is licensed under a Creative Commons Attribution 4.0 International License, which permits use, sharing, adaptation, distribution and reproduction in any medium or format, as long as you give appropriate credit to the original author(s) and the source, provide a link to the Creative Commons licence, and indicate if changes were made. The images or other third party material in this article are included in the article's Creative Commons licence, unless indicated otherwise in a credit line to the material. If material is not included in the article's Creative Commons licence and your intended use is not permitted by statutory regulation or exceeds the permitted use, you will need to obtain permission directly from the copyright holder. To view a copy of this licence, visit http://creativecommons.org/licenses/by/4.0/. The Creative Commons Public Domain Dedication waiver (http://creativecommons.org/publicdomain/zero/1.0/) applies to the data made available in this article, unless otherwise stated in a credit line to the data. 
tumor growth-inhibiting or tumor-killing genes [9]. RNA interference has been used in gene therapy to inhibit tumorigenesis and proliferation [10]. In addition, suicide gene [11], oncolytic virus [12], and immunomodulatory gene [13] have widely been applied in cancer gene therapy. The key to gene therapy is the use of safe and effective gene delivery vectors, such as viral and non-viral vectors. Fortunately, a variety of viral vectors including adenovirus [14], herpes simplex virus [15], and adenoassociated virus (AAV) [16] have been widely applied in the treatment of clinical and experimental cancer disease models. Among them, AAV, as an important viral vector, exerts a strong potential in the treatment of cancer diseases [17].

AAV vectors are promising in gene therapy for their stable, efficient, and non-cytotoxic gene delivery to transduce a great number of tissues of different mammalian species, including the CNS, and are one of the most commonly used viral vectors in gene therapy $[18,19]$. Currently, AAV has been used as a vector for gene therapy in multiple clinical trials (more than 100) to target lung, liver, eye, brain, and muscle and has achieved great success in blindness and hemophilia diseases [20]. AAV1 vector-encoded lipoprotein lipase became the first gene therapy product (Glybera) approved to treat lipoprotein lipase deficiency by the European Union in 2012 [21]. Five years later, another AAV-mediated gene therapy drug (Luxturna) was subsequently approved for marketing in the U.S. [22]. Just last year, AAV9-based gene therapy (Zolgensma) has also been marketed to treat spinal muscular atrophy [23]. These development greatly inspired researchers to further explore the function of $\mathrm{AAV}$ as a gene therapy vector. AAV-mediated gene therapy strategies include gene replacement, gene silencing, and gene editing [17]. Recently, AAVs that deliver therapeutic agents have been utilized for the treatment of experimental GBM mice model and remarkably inhibited the growth of GBM cells and prolongs the survival rate of GBM mice [24]. Due to the presence of BBB, AAV that deliver therapeutic agents for the treatment of experimental GBM model are administered by intracranial local injection, which indeed relieves non-invasive experimental GBM in mice model $[25,26]$. However, intracranial injection entails surgical risks and clinical costs and makes the scope of treatment relatively limited [27]. Human GBM cells are highly invasive and can migrate along blood vessels to areas of the brain away from the tumor bulk. This factor poses a big challenge for intracranial injection [28]. Researchers have also tried intracerebroventricular (ICV) injection to deliver AAV vectors to treat GBM. ICV injection can solve the relatively limited diffusion of AAV vectors in local injection to a certain extent and improves the therapeutic effect on invasive experimental GBM mouse model [29]. Instability and inevitable invasiveness are the drawbacks of ICV injection [30]. The development of BBB-crossing AAV make the systematic injection of AAV possible to treat GBM [31]. Systematic delivery, also called intravenous injection, can achieve widespread gene delivery and minimize invasive surgery; thus, this approach would be ideal for treating CNS diseases, including GBM [32, 33]. However, systematic injection in AAV-based GBM gene therapy also has some problems, including the low efficiency of AAV crossing the BBB, pre-existing AAV-neutralizing antibodies in the body, peripheral toxicity, and inability to target specific cells [34-37].

In this review, we systematically introduced the prospects of AAV-based gene therapy for GBM and compared the advantages and disadvantages of different AAV injection methods. Most importantly, we will focus on the feasibility of the systematic injection of AAV for the treatment of GBM and the challenge faced by systematic injection.

\section{AAV characteristics and its role in cancer gene therapy AAV structure and composition}

AAV was accidentally found in the 1960s during a laboratory preparation of adenovirus and later found in human tissues [38]. AAV does not cause any human diseases, and its life cycle is connected with a helper virus (such as adenovirus and herpes simplex virus). AAV cannot replicate independently, and its replication and cytolytic functions can only be performed under the presence of helper viruses $[39,40]$. AAV does not integrate with the host's genome and can stably express transgenes for a long period. In addition, AAV is widespread in many species, including human and non-human primates, and is highly infectious to a variety of tissue cells in vivo with non-pathogenic quality; thus, AAV has become the star vector for gene therapy $[41,42]$.

AAV is a single-stranded linear DNA-deficient virus with a genomic DNA of less than $5 \mathrm{~kb}$, and its structure is icosahedral non-enveloped particle. AAV is composed of one single-stranded DNA with inverse terminal repeat (ITR) sequence and two open reading frames Rep and Cap at both ends. ITRs are symmetrical repeats that play important roles in the structure and function of AAV. The Rep gene comprises four overlapping genes Rep78, Rep68, Rep52, and Rep40 and can encode the Rep protein required for AAV replication, package, and genomic integration. Cap gene is composed of overlapping amino acid sequences and encodes the capsid protein, including VP1, VP2, and VP3 with a ratio of 1:1:10 (VP1:VP2:VP3). These three interact with each other to 
form a symmetrical icosahedron structure, which acts as a vehicle for gene delivery $[43,44]$.

\section{AAV-based cancer gene therapy}

AAV-based gene therapy has been applied in a variety of preclinical and clinical trials to date and has shown a strong safety profile and trustworthy therapeutic effects [16]. In recent years, AAV has shown great value in the treatment of tumor diseases. Two clinical trials of AAVbased cancer gene therapy have been reported. One is the single injection of carcinoembryonic antigen (CEA)specific cytotoxic $\mathrm{T}$ lymphocyte, which is activated by AAV2-CEA-transduced dendritic cells, to treat patients with advanced gastric cancer (ClinicalTrials.gov Identifier: NCT02496273), and the other is AAV2-hAQP1 applied in patients with squamous cell head and neck cancer (ClinicalTrials.gov Identifier: NCT02602249). In the treatment of cancer diseases, AAV can transduce a large number of cancer cells and cancer stromal cells and stably express cancer therapeutic genes (suicide gene, immunostimulatory gene, cytotoxic gene, small interference (siRNA) and anti-angiogenesis gene) to inhibit cancer formation and progression [45, 46]. The biggest problem with AAV-based cancer gene therapy is how to make AAV more specifically transduce to the cancer region [47]. Hence, a variety of rational designs of capsid have been engineered for cancer-specific transduction. Aminopeptidase N (CD13) is highly expressed in tumor tissues. Thus, Grifman et al. engineered AAV2 capsid by inserting an NGR peptide motif, which made AAV2 deliver therapeutic agents more efficiently and specifically to tumor cells [48]. Integrin is highly expressed on cancer vessels and cancer tissues and is used as an indicator of poor cancer prognosis. A study modified the AAV2 capsid by introducing a 4C-RGD peptide, which could efficiently combine $\alpha v \beta 3$ and $\alpha v \beta 5$ integrins. This modification promotes AAV2-mediated gene delivery to integrin-positive cancer cells in vitro and in vivo [49]. In addition, another study fused designed ankyrin repeat proteins to AAV2 capsid VP2 to target the cancer-associated receptor human epidermal growth factor receptor 2 (HER2)/neu. Her2-AAV selectively and highly transduces Her2-positive tumor cells and weakly transduces other cells, which greatly reduces its toxicity to other normal tissues [50]. AAV5 has also been engineered for cancerspecific transduction. Lee et al. engineered AAV5 with integrin-homing peptides, sialyl Lewis $\mathrm{X}$ and tenacin $\mathrm{C}$, which are highly expressed in cancer cells [51]. Cheng et al. mutated tyrosine residues on AAV3 to phenylalanine, which increased the transduction capacity to hepatocellular carcinoma cells [52]. AAV capsid engineering promotes the effect of cancer cell-specific transduction to more effectively deliver therapeutic agents to the tumor site and greatly improve the treatment effect of AAVbased cancer therapy. The specific transduction of AAV is particularly important in AAV-based GBM gene therapy. How to make AAV specifically transduce to CNS regions and greatly reduce the peripheral toxicity of therapeutic genes especially in systematic injection approach are the key steps in AAV-based GBM gene therapy.

\section{AAV-based experimental trials on GBM mice model}

AAV has been used to treat experimental GBM model for decades because of their stable and persistent expression of anti-tumor agents in transduced cells [53]. After the first discovery that AAV-encoded tumor suppressor genes could effectively inhibit the growth of GBM cell lines in vitro, AAV emerged as an effective delivery tool for the treatment of experimental GBM model [54]. Previously, AAV-based GBM therapy was administered by local injection because of the $\mathrm{BBB}$, which blocks the path of AAV to the GBM [55]. Researchers have also tried the ICV route to deliver AAV directly into the cerebrospinal fluid to further penetrate into the brain parenchyma to treat experimental GBM mouse models and have achieved certain success [56]. The recent discovery of BBB-crossing AAV introduced a new approach, namely, the systematic injection of AAV, to fight GBM. Systematic injection seems a better treatment approach than local or ICV injection because of its non-invasiveness and broad transduction [57] (Fig. 1). AAV-mediated experimental gene therapy against GBM utilizes a variety of therapeutic strategies, such as tumor suppression and the use of anti-tumor genes, including anti-angiogenesis genes, cytotoxic or suicide genes, and immunostimulatory genes [58]. Next, we will systematically summarize the progress of AAV-based GBM research in several in vivo delivery routes and in vitro findings (Table 1).

\section{Anti-GBM effect of $A A V$ in vitro}

It is reported that the hypoxia-regulated AAV was first used to kill GBM cells in 2001 in vitro. They constructed a hypoxia-regulated AAV, which can encode the suicide gene $B a x$ for the hypoxic GBM microenvironment. Their result showed that $B a x$ was abundantly expressed under hypoxic condition after AAV transduction and promoted the death of GBM cells in vitro [54].Tumor necrosis factor-related apoptosis-inducing ligand(TRAIL), which induces tumor cell apoptosis but is less toxic to normal tissues, has been used in the treatment of various tumor diseases. Shawn et al. developed AAV-soluble TRAIL (sTRAIL), which could transduce GBM cells to promote the killing effect on GBM cells and increase pro-apoptotic protein level in GBM cells in vitro [59]. PTEN is the most common mutant tumor suppressor gene in various tumor diseases including GBM. Mutant PTEN rescued 


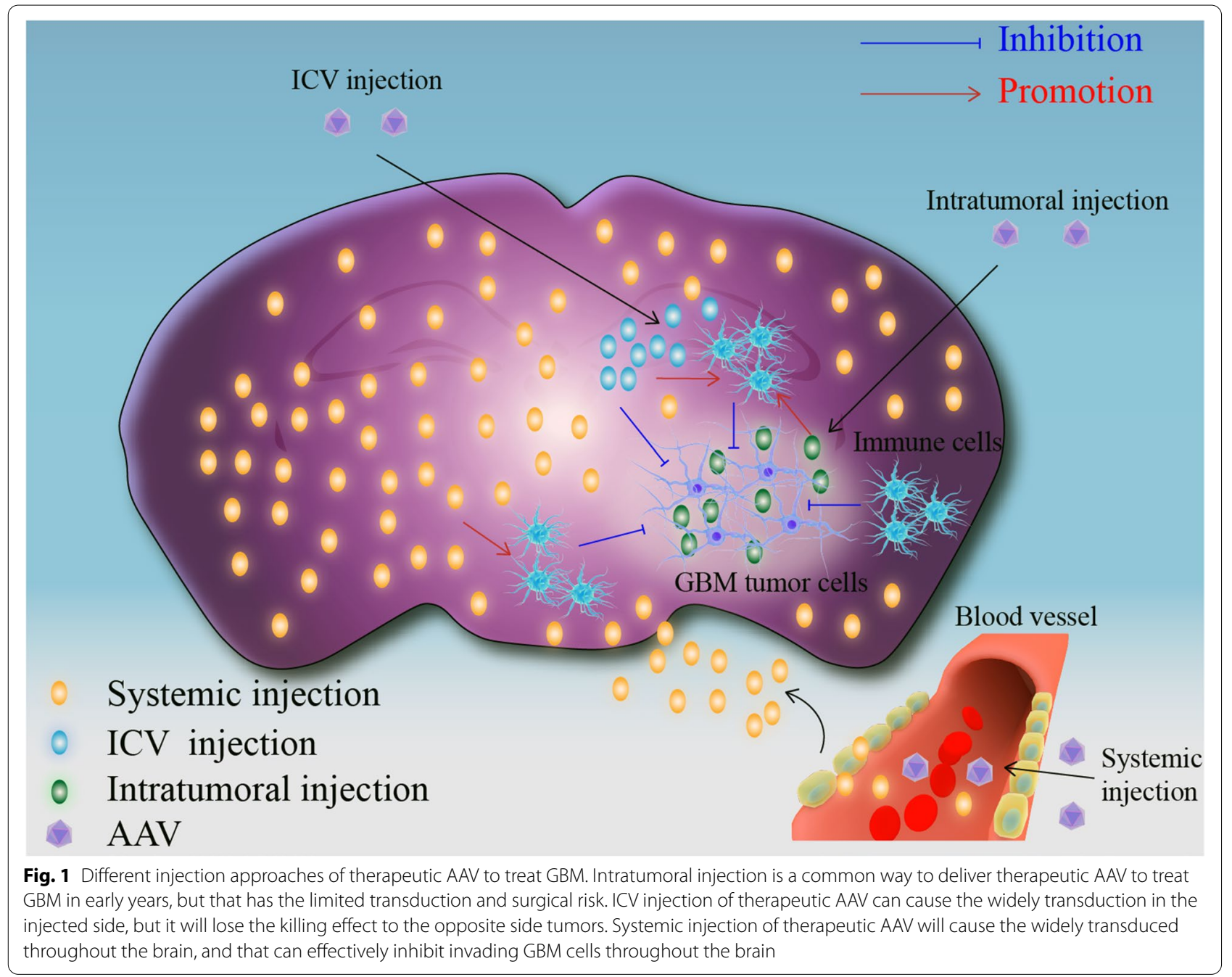

\section{Table 1 Different factors delivered by AAV to treat GBM}

\begin{tabular}{llll}
\hline Factor & AAV serotype & Delivered approach & References \\
\hline HSV-tk & - & Intratumoral injection & {$[62]$} \\
IFN- $\beta$ & AAV2 & Intratumoral injection & {$[63]$} \\
SVEGFR1/R2 & - & Intratumoral injection & {$[25]$} \\
Anti-VEGF & AAVrh.10 & Intratumoral injection & {$[64]$} \\
TFPI-2 & - & Intratumoral injection & {$[65]$} \\
hTERTC27 & - & Intratumoral injection & {$[66]$} \\
Decorin & AAV2 & Intratumoral injection & {$[61]$} \\
TRAIL & AAVrh.8 & Intratumoral injection & {$[67]$} \\
ADP & AAV2 & Intratumoral injection & {$[55]$} \\
MiR-7 & - & Intratumoral injection & {$[68]$} \\
IFN- $\beta$ & - & ICVinjection & {$[29]$} \\
STRAIL & AAV9 & Systematic injection & {$[78]$} \\
IFN- $\beta$ & AAV9 & Systematic injection & {$[80]$} \\
\hline
\end{tabular}

by gene editing can inhibit the proliferation of tumor cells. Thus, Victoria et al. developed AAV-mediated gene editing, which effectively modified the mutant PTEN gene in GBM cells and inhibited the proliferation and growth of GBM cells. The AAV-mediated killing of GBM cells in vitro indicates the feasibility of AAV-based GBM gene therapy [60].

\section{Anti-GBM effect of AAV through intratumoral injection}

Intratumoral injection is the most generally preferred method for AAV to treat the experimental GBM mice model because of the presence of $\mathrm{BBB}$. The local injection of AAV, which deliver therapeutic agents, has inhibited the growth of intracranial GBM and prolonged the survival rate of tumor-bearing mice to some extent [61]. AAV-based GBM therapy was first applied to treat experimental GBM mice model in 1996, Their study proved that a single intracranial injection of AAV-tk-IRES-IL-2 could effectively prohibit 
the progression of xenograft GBM. One year later their laboratory colleagues proved that the intracranial injection of AAV-tk and the intraperitoneal injection of gancyclovir could eliminate tumors in GBM mice [62]. However, despite its excellent result, the approach has serious hepatotoxicity, and its use has been stranded. Interferon-beta (IFN- $\beta$ ) has potent antitumor effects by inhibiting the growth and angiogenesis of cancer cells and promoting cancer cell apoptosis and immune stimulation. Since 2002, several researchers have tried to overcome the experimental GBM mice model by administering AAV-encoding IFN- $\beta$ through local injection and have achieved certain effects [63]. Vascular endothelial growth factor (VEGF), as a proangiogenic factor, is remarkably upregulated in GBM tissue and promotes angiogenesis and growth of GBM tumors. Thus, AAV-delivered sVEGFR1/R2, a kind of VEGF-optimized soluble inhibitor, was used to treat experimental GBM model. Their result showed the powerful anti-GBM effect exerted by the local injection of AAV-sVEGFR1/R2 [25]. Furthermore, Some studies also found that bevacizumab, an anti-VEGF monoclonal antibody, delivered by AAVrh.10 could reduce the blood vessel density and volume of GBM tumor and increase survival rate [64]. Tissue factor pathway inhibitor-2 (TFPI-2) has a strong ability to inhibit tumor cell proliferation, migration, and angiogenesis. Niranjan et al. found that AAV-TFPI-2 could mediate the inhibition of GBM progression in vitro and in vivo [65]. It is reported that the overexpression of the C-terminal fragment of the human telomerase reverse transcriptase (hTERTC27) can prohibit the occurrence of malignant tumors including the experimental GBM model. Evidence has shown that intratumoral injection of AAV-hTERTC27 could inhibit the growth of xenograft GBM, amplify tumor necrosis and apoptosis, and reduce microvessel density in nude mice [66]. In addition, studies have shown that AAV2 intratumoraldelivered decorin, which exerted anti-tumor effect by affecting the epidermal growth factor receptor, transforming growth factor-beta, and p21, could inhibit GBM and prolong the survival of GBM mice [61]. Studies shown that AAV-secreted TRAIL (S-TRAIL) could promote the killing effect on GBM cells in vitro. Here, AAVrh.8-S-TRAIL accompanied with the administration of lanatoside $\mathrm{C}$ was proved to increase the overall survival of U87 bearing mice and that further confirm the anti-GBM role of S-TRAIL [67]. It is also clarified that AAV2-apoptin-derived peptide (ADP) promoted the apoptosis of GBM cells and prolonged the survival rate of orthotopic GBM bearing mice s[55]. Previous studies have shown that microRNAs could inhibit tumorigenesis. Here, studies have proved that AAV-miR-7 significantly reduced the tumor size, upregulated death receptor 5 to promote the tumor cell death and prolonged the survival in xenografts GBM mice model [68].

The intracranial injection of AAV circumvents the obstacles of BBB. Compared with the injection of pure therapeutic protein, AAV's persistent and stable expression of therapeutic agents can better inhibit the sustained development of GBM [69]. This was indeed the reason for the popularity of AAV-based GBM treatment approach in the early years. The above research also shows that the local injection of AAV delivering some traditional or GBM-specific anti-tumor genes is effective and, to some extent, alleviates the progress of experimental GBM mice model. Locally injected therapeutic AAV has been reported to infiltrate into the tumor area, but the AAV genome will be diluted because of the rapid growth and division of GBM tumor cells; this dilution will results in the reduced expression efficiency and affects the therapeutic effect [27]. In addition, studies have shown that the local injection of AAV with partial area transduction in the brain can only have a good effect on noninvasive, implanted GBM tumors, but human GBM is highly invasive. GBM cells can migrate along blood vessels away from the tumor core; thus, the local injection of AAV could hardly eliminate all the invasive distant GBM cells [70, 71]. Owing to the invasive nature of GBM cells, a globally spread gene delivery vehicle is badly needed to combat the diffused primary tumor or tumor recurrence. Studies have demonstrated proved that the injection of ssAAV2-ADP in the left hemisphere effectively prevents the growth of ipsilateral tumors but is not enough to prevent the growth of distal tumors in the contralateral hemisphere [55]. Furthermore, Matheus et al. showed that the intracranial injection of AAVrh8-sTRAIL indeed extends the survival rate of experimental GBM mice, but these mice also died of tumor spread within 100 days. Therefore, the local injection of AAV to treat human GBM is still very flawed and will not achieve the desired therapeutic effect. The researchers also demonstrated that the therapeutic gene must be widely expressed in the brain to fight against invasive GBM cells [67]. One way to achieve this goal is to systematically inject BBB-crossing AAV, which can perform extensive gene delivery in the brain.

\section{Anti-GBM effect of AAV through ICV injection}

The ICV injection of therapeutic drugs is a common approach for the treatment of CNS diseases. In recent years, ICV injection is also widely used because it allows therapeutic drugs to reach most of the brain regions with the circulation of cerebrospinal fluid in the treatment of experimental GBM mice model [72]. Studies have shown that the ICV injection of AAV can overcome 
the disadvantages of local injection in GBM treatment. It is reported that intracranial fixed-point injection cannot completely eliminate distant infiltrating GBM cells because of the extensive infiltration and migration characteristics of GBM cells. They showed that the pre-injection of AAV vector encoding human IFN- $\beta$ (AAV-IFN- $\beta$ ) through ICV injection can completely prevent tumor growth in an orthotopic model of GBM [29]. In addition, the survival rate of pre-established U87 intracranial tumor mice injected with AAV-IFN- $\beta$ through ICV was substantially improved compared with injecting the control AAV vector through the same route. These data indicate that the ICV injection of AAV vectors that encode anti-tumor proteins is a promising method and deserves further study. Compared with local injection, the ICV injection of AAV can eliminate most of the distant GBM cells. Furthermore, local injection is highly dangerous when GBM is located in the critical structure of the brain, and ICV injection can well avoid this problem [73]. However, ICV injection also has defects. First, ICV injection is unstable. Second, ICV injection delivers AAV into the cerebrospinal fluid, which only circulates between the ventricles. The brain parenchyma area close to the ventricle may have good transduction, but the transduction efficiency for areas away from the brain ventricle may not be enough [56, 74]. Furthermore, other studies [29] demonstrated that AAV delivered by ICV injection also has chemotaxis in the brain, mostly transduces the hippocampus and corpus callosum, but rarely transduces other parts. From this point of view, AAV-based GBM gene therapy through ICV injection is also inadequate. Searching for a better delivery method that can make AAV transduce the entire CNS is a key step in AAVbased GBM gene therapy.

\section{Anti-GBM effect of AAV through systematic injection}

The discovery of BBB-crossing AAV9 opened the door to the systematic injection of AAV for CNS diseases in 2009 [33]. BBB-crossing rAAVrh.8 and rAAVrh.10, which played a role in promoting the systematic injection of therapeutic AAV to treat CNS diseases, were discovered in 2014 [75]. To date, AAV9, AAVrh.8, AAVrh.10, AAVrh.39, and AAVrh.43 have been proved to have the ability to transduce glial and neurons after systemic injection [76]. AAV9 variants AAV-PHP.B and AAVPHP.eB, which were developed by researchers through directed evolution approach, also have excellent CNS transduction ability in C57 mice [77, 78]. After the discovery of these BBB-crossing AAVs, researchers began to treat experimental GBM mice model with therapeutic AAV by systematic injection. It is the first time that the systematic injection of AAV was applied to treat GBM in 2016. Their result showed that systematic administration of AAV9-sTRAIL suppressed tumor growth and remarkably increased the survival of xenograft GBM mice [79]. Some studies also proved that systematic AAV9-IFN- $\beta$ delivery could induce complete tumor regression in experimental GBM model in a dose-dependent manner. They also demonstrated that the systematic administration of AAV9-IFN- $\beta$ is more efficient in multifocal GBM compared with local injection [80]. In recent years, the systematic injection of therapeutic AAV in GBM treatment has attracted considerable attention with the development of AAV9 variants AAV-PHP.B and AAV-PHP. $\mathrm{eB}$, which have been proven to have a stronger ability to cross the BBB than AAV9.

The systematic injection of therapeutic AAV has extensive transduction characteristics and fundamental advantages over local injection or ICV injection; thus, this approach is an excellent way to treat GBM [80] (Table 2). A great number of studies have shown that systemically injected therapeutic AAV can transduce most regions of the CNS through the extensive vascular system and has a comprehensive containment effect on invasive, malignant GBM [81, 82]. It is reported that proved that the effect of the systematic injection of AAV9-IFN-ßin treating multifocal GBM is better than that of local injection [80]. Moreover, ICV injection can only inhibit ipsilateral GBM tumors but not the tumors in the contralateral side because of its limitations in transduction [29]. These results clearly showed the advantages of the systematic injection of AAV in the treatment of GBM. Human GBM is highly invasive and can spread widely in the brain; thus, systemic injection is the best choice for AAV-based GBM gene therapy to eliminate GBM more thoroughly [83]. Despite its advantages compared with local injection and ICV injection, the systematic injection of AAV-based GBM gene therapy faces a variety of challenges that need

Table 2 Comparison of different injection approaches of AAV-based GBM gene therapy

\begin{tabular}{|c|c|c|c|}
\hline Injection approaches & Advantage & Disadvantage & References \\
\hline Intratumoral injection & Overcomes the BBB obstacle & Transduces region limitation, Surgical risk & {$[70,71]$} \\
\hline ICVinjection & $\begin{array}{l}\text { Good transduction for the brain parenchyma } \\
\text { area close to the ventricle }\end{array}$ & $\begin{array}{l}\text { Instability of ICV injection, Only the hemibrain has good } \\
\text { transduction }\end{array}$ & {$[56,74]$} \\
\hline Systematic injection & Extensive transduction throughout the brain & Immune barrier, neutralizes antibodies in the blood & {$[76,87]$} \\
\hline
\end{tabular}


to be resolved [84]. The first challenge is the efficiency of $\mathrm{BBB}$ crossing. $\mathrm{BBB}$ is the main obstacle that hinders the entry of therapeutic drugs into the CNS. How to overcome the $\mathrm{BBB}$ and transduce more efficiently into the CNS are the most critical steps in the systematic injection of AAV-based GBM gene therapy [85, 86]. Although some AAVs that can cross the BBB have been developed, more efficient AAV mutants still need to be studied. The second challenge is the non-specificity of AAV transduction. Systematic injection can widely distribute AAV in various parts of the body; hence, the expression of therapeutic gene in non-target cells away from the disease site is also very high and may result in ineffective treatment and high peripheral toxicity. The last challenge is the immune barrier [87]. Therapeutic AAV can be neutralized because of the large amount of AAV antibody in the human blood, which results in poor treatment effect or even no effect. Therefore, finding possible solutions to the challenges of systematic injection is the key in AAVbased GBM gene therapy.

\section{Conclusions and future prospects}

GBM is a highly malignant intracranial tumor that is highly aggressive and heterogeneous. Surgical resection combined with radiotherapy and chemotherapy is the main method for the clinical treatment of GBM, but patient survival rate is still very low [88]. The development of gene therapy has been widely used in a great number of diseases. AAV has become a focus in gene therapy because of its stable, non-pathogenic, and longterm expression of therapeutic agents. AAV has been used for decades to deliver therapeutic agents to treat experimental GBM in mice model [89]. AAV-based GBM therapy is mainly administered by local injection in the early years because of the BBB [55]. Although this approach is damaging and can only achieve partial transduction in the CNS region, it plays a role in extending the survival rate of experimental GBM mice model. The discovery of BBB-crossing AAV9 in 2009 introduced the systematic injection of AAV to treat GBM. Systematic injection is noninvasive and has superior wide-spread transduction than local injection, especially for the treatment of highly aggressive tumors, such as GBM [33]. The systematic injection of therapeutic AAV has great advantages over local injection in the treatment of aggressive GBM [80] but also faces many challenges. Developing more efficient $\mathrm{BBB}$-crossing AAV, performing AAV-specific CNS transduction, and reducing peripheral toxicity are the main challenges [87]. Researchers have used multiple genetic engineering techniques to make AAV capsid have the ability to cross the BBB and search for new BBBcrossing AAV serotypes [90]. Until now, a great number of BBB-crossing AAV mutants are being developed, including the AAV-PHP.B and AAV-PHP.eB, which can transduce the entire CNS region. Peripheral toxicity, especially liver toxicity, have been addressed through some countermeasures, such as inserting CNS-specific promoters or using microRNA to suppress peripheral transgene expression [91, 92], but cannot be completely eliminated. Thus, developing an AAV capable of CNSspecific tropism without infecting peripheral tissue is a direction worthy of further research. Compared with other viral vectors such as oncolytic viruses, AAV vectors have unique advantages. Although the oncolytic virus has a direct cytotoxic effect on GBM tumor cells, the AAV vector has the advantages of stability, high efficiency, and long-term continuous expression of therapeutic genes, which is more conducive to the durable inhibitory effect of therapeutic genes on GBM. Furthermore, AAV also has BBB-crossing ability, which poses the possibility of intravenous injection of gene therapy for GBM treatment, which is incomparable to other viral vectors. In conclusion, the systematic injection of AAV for the treatment of GBM is a promising direction, but some work needs to be studied further: developing more efficient BBB-crossing AAV, enhancing the CNS-specific transduction of $\mathrm{AAV}$, and reducing peripheral toxicity.

\section{Abbreviations}

GBM: Glioblastoma multiforme; AAV: Adeno-associated virus; ICV: Intracerebroventricular; CNS: Central nervoussystem; BBB: Blood-brain barrier; ITR: Inverted terminalrepeat; VEGF: Vascular endothelialgrowth factor; TFPI-2: Tissue factor pathwayinhibitor-2; hTERTC27: Human telomerasereverse transcriptase; ADP: Apoptin-derivedpeptide; miR: MicroRNA; DR5: Death receptor 5.

\section{Acknowledgements}

We thank Jie Wan for the help with this manuscript.

\section{Authors' contributions}

$X X, W C$, and WZ wrote the manuscript. JC, BM, and JD revised the manuscript. $Z W$ and $Y L$ drew the figures and modified the language. $X X, X Z$, and $Y W$ designed the study. All authors read and approved the final manuscript.

\section{Funding \\ This work was supported by Jiangsu Natural Science Foundation Youth Project (Grant BK20180277), The Second Traditional Chinese Medicine Leadership Training Foundation of Jiangsu Province and Youth Fund Project of Basic research program of Jiangsu Province (Grant BK21080278).}

Availability of data and materials

Not applicable.

Ethics approval and consent to participate

Not applicable.

\section{Consent for publication}

Not applicable.

\section{Competing interests}

The authors declare that they have no competing interests.

\section{Author details}

${ }^{1}$ School of Medicine, Jiangsu University, Zhenjiang 212013, Jiangsu, China. ${ }^{2}$ Department of Neurosurgery and Pituitary Tumor Center, The First 
Affiliated Hospital, Sun Yat-sen University, Guangzhou, China. ${ }^{3}$ Department of Laboratory Medicine, The Second People's Hospital of Lianyungang, Lianyungang 222006, China. ${ }^{4}$ Department of Hepatobiliary Surgery, The Second People's Hospital of Lianyungang, Lianyungang 222006, Jiangsu, China. ${ }^{5}$ School of Medicine, Yangzhou University, Yangzhou 225600, China. ${ }^{6}$ Department of Oncology, Yangzhou Traditional Chinese Medical Hospital, Yangzhou 225600, Jiangsu, China.

Received: 15 October 2020 Accepted: 16 January 2021

Published online: 26 January 2021

\section{References}

1. Aldape K, Zadeh G, Mansouri S, Reifenberger G, von Deimling A. Glioblastoma: pathology, molecular mechanisms and markers. Acta Neuropathol. 2015;129(6):829-48

2. Lee JH, Lee JE, Kahng JY, Kim SH, Park JS, Yoon SJ, Um JY, Kim WK, Lee JK, Park J, et al. Human glioblastoma arises from subventricular zone cells with low-level driver mutations. Nature. 2018;560(7717):243-7.

3. Stupp R, Mason WP, van den Bent MJ, Weller M, Fisher B, Taphoorn MJ, Belanger K, Brandes AA, Marosi C, Bogdahn U, et al. Radiotherapy plus concomitant and adjuvant temozolomide for glioblastoma. New Engl J Med. 2005:352(10):987-96.

4. Wirsching HG, Galanis E, Weller M. Glioblastoma. Handb Clin Neurol. 2016;134:381-97.

5. Xie J, Shen Z, Anraku Y, Kataoka K, Chen X. Nanomaterial-based bloodbrain-barrier (BBB) crossing strategies. Biomaterials. 2019;224:119491.

6. Brody H. Gene therapy. Nature. 2018;564(7735):S5.

7. Ikawa Y, Miccio A, Magrin E, Kwiatkowski JL, Rivella S, Cavazzana M. Gene therapy of hemoglobinopathies: progress and future challenges. Hum Mol Genet. 2019:28(R1):R24-r30.

8. High KA, Roncarolo MG. Gene Therapy. N Engl J Med. 2019;381(5):455-64.

9. McCrudden CM, McCarthy HO. Current status of gene therapy for breast cancer: progress and challenges. Appl Clin Genet. 2014;7:209-20.

10. Zhong X, Zhang D, Xiong M, Zhang L. Noncoding RNA for Cancer Gene Therapy. Recent Results Cancer Res Fortschritte der Krebsforschung Progres dans les recherches sur le cancer. 2016;209:51-60.

11 Hossain JA, Marchini A, Fehse B, Bjerkvig R, Miletic H. Suicide gene therapy for the treatment of high-grade glioma: past lessons, present trends, and future prospects. Neurooncol Adv. 2020;2(1):vdaa013.

12. Mühlebach MD. Measles virus in cancer therapy. Curr Opin Virol. 2020:41:85-97.

13. Núñez Selles AJ, Daglia M, Rastrelli L. The potential role of mangiferin in cancer treatment through its immunomodulatory, anti-angiogenic, apoptopic, and gene regulatory effects. BioFactors (Oxford, England). 2016;42(5):475-91.

14. Nattress CB, Halldén G. Advances in oncolytic adenovirus therapy for pancreatic cancer. Cancer Lett. 2018;434:56-69.

15. Cao S, Gan Y, Dong X, Lu Z. Herpes simplex virus type 2 and the risk of cervical cancer: a meta-analysis of observational studies. Arch Gynecol Obstet. 2014;290(6):1059-66.

16. Santiago-Ortiz JL, Schaffer DV. Adeno-associated virus (AAV) vectors in cancer gene therapy. J Control Release. 2016;240:287-301.

17 Luo J, Luo Y, Sun J, Zhou Y, Zhang Y, Yang X. Adeno-associated virusmediated cancer gene therapy: current status. Cancer Lett. 2015;356(2 Pt B):347-56.

18. Li C, Bowles DE, van Dyke T, Samulski RJ. Adeno-associated virus vectors: potential applications for cancer gene therapy. Cancer Gene Ther. 2005;12(12):913-25.

19. McCown TJ. Adeno-associated virus (AAV) vectors in the CNS. Curr Gene Ther. 2005;5(3):333-8.

20. Naso MF, Tomkowicz B, Perry WL 3rd, Strohl WR. Adeno-associated virus (AAV) as a vector for gene therapy. BioDrugs Clin Immunother Biopharm Gene Ther. 2017;31(4):317-34.

21. Ylä-Herttuala S. Glybera's second act: the curtain rises on the high cost of therapy. Mol Ther J Am Soc Gene Ther. 2015;23(2):217-8.

22. Patel U, Boucher M, de Léséleuc L, Visintini S. Voretigene neparvovec: an emerging gene therapy for the treatment of inherited blindness.
In: CADTH issues in emerging health technologies. Ottawa: Canadian Agency for Drugs and Technologies in Health Copyright (c) CADTH 2018. You are permitted to reproduce this document for non-commercial purposes, provided it is not modified when reproduced and appropriate credit is given to CADTH. 2016. p. 1-11.

23. Hoy SM. Onasemnogene abeparvovec: first global approval. Drugs. 2019:79(11):1255-62.

24. Maguire CA, Gianni D, Meijer DH, Shaket LA, Wakimoto H, Rabkin SD, Gao G, Sena-Esteves M. Directed evolution of adeno-associated virus for glioma cell transduction. J Neurooncol. 2010;96(3):337-47.

25. Harding TC, Lalani AS, Roberts BN, Yendluri S, Luan B, Koprivnikar KE, Gonzalez-Edick M, Huan-Tu G, Musterer R, VanRoey MJ, et al. AAV serotype 8-mediated gene delivery of a soluble VEGF receptor to the CNS for the treatment of glioblastoma. Mol Ther J Am Soc Gene Ther. 2006;13(5):956-66.

26. Krolicki L, Bruchertseifer F, Kunikowska J, Koziara H, Królicki B, Jakuciński M, Pawlak D, Apostolidis C, Mirzadeh S, Rola R, et al. Prolonged survival in secondary glioblastoma following local injection of targeted alpha therapy with (213)Bi-substance P analogue. Eur J Nucl Med Mol Imaging. 2018;45(9):1636-44.

27. Volak A, LeRoy SG, Natasan JS, Park DJ, Cheah PS, Maus A, Fitzpatrick Z, Hudry E, Pinkham K, Gandhi S, et al. Virus vector-mediated genetic modification of brain tumor stromal cells after intravenous delivery. J Neurooncol. 2018;139(2):293-305.

28. Lee E, Yong RL, Paddison P, Zhu J. Comparison of glioblastoma (GBM) molecular classification methods. Semin Cancer Biol. 2018;53:201-11.

29. Meijer DH, Maguire CA, LeRoy SG, Sena-Esteves M. Controlling brain tumor growth by intraventricular administration of an AAV vector encoding IFN-beta. Cancer Gene Ther. 2009;16(8):664-71.

30. Kawasaki H, Kosugi I, Sakao-Suzuki M, Meguro S, Tsutsui Y, Iwashita T. Intracerebroventricular and intravascular injection of viral particles and fluorescent microbeads into the neonatal brain. J Vis Exp JoVE. 2016;113:e54164.

31. Manfredsson FP, Rising AC, Mandel RJ. AAV9: a potential blood-brain barrier buster. Mol Ther J Am Soc Gene Ther. 2009;17(3):403-5.

32. Saunders NR, Joakim Ek C, Dziegielewska KM. The neonatal blood-brain barrier is functionally effective, and immaturity does not explain differential targeting of AAV9. Nat Biotechnol. 2009;27(9):804-5 (author reply $\mathbf{8 0 5}$ )

33. Foust KD, Nurre E, Montgomery CL, Hernandez A, Chan CM, Kaspar BK. Intravascular AAV9 preferentially targets neonatal neurons and adult astrocytes. Nat Biotechnol. 2009;27(1):59-65.

34. Albright BH, Storey CM, Murlidharan G, Castellanos Rivera RM, Berry GE, Madigan VJ, Asokan A. Mapping the structural determinants required for AAVrh. 10 transport across the blood-brain barrier. Mol Ther. 2018;26(2):510-23.

35. Barnes C, Scheideler O, Schaffer D. Engineering the AAV capsid to evade immune responses. Curr Opin Biotechnol. 2019;60:99-103.

36. Lykken EA, Shyng C, Edwards RJ, Rozenberg A, Gray SJ. Recent progress and considerations for AAV gene therapies targeting the central nervous system. J Neurodev Disord. 2018;10(1):16.

37. Rabinowitz J, Chan YK, Samulski RJ. Adeno-associated Virus (AAV) versus immune response. Viruses. 2019;11(2):102.

38. Berns KI, Muzyczka N. AAV: an overview of unanswered questions. Hum Gene Ther. 2017;28(4):308-13.

39. Coura Rdos S, Nardi NB. The state of the art of adeno-associated virusbased vectors in gene therapy. Virol J. 2007;4:99.

40. Van Vliet KM, Blouin V, Brument N, Agbandje-McKenna M, Snyder RO. The role of the adeno-associated virus capsid in gene transfer. Methods Mol Biol (Clifton, NJ). 2008:437:51-91.

41. Hastie E, Samulski RJ. Adeno-associated virus at 50: a golden anniversary of discovery, research, and gene therapy success-a personal perspective. Hum Gene Ther. 2015;26(5):257-65.

42. Ozawa K. Gene therapy using AAV. Uirusu. 2007;57(1):47-55.

43. Grimm D, Büning $H$. Small but increasingly mighty: latest advances in AAV vector research, design, and evolution. Hum Gene Ther. 2017;28(11):1075-86.

44. Wu Z, Asokan A, Samulski RJ. Adeno-associated virus serotypes: vector toolkit for human gene therapy. Mol Ther J Am Soc Gene Ther. 2006;14(3):316-27. 
45. Hacker UT, Bentler M, Kaniowska D, Morgan M, Büning H. Towards clinical implementation of adeno-associated virus (AAV) vectors for cancer gene therapy: current status and future perspectives. Cancers. 2020;12(7):1889.

46. Britten CM, Walter S, Janetzki S. Immunological monitoring to rationally guide AAV gene therapy. Front Immunol. 2013;4:273.

47. Ernst MPT, Broeders M, Herrero-Hernandez P, Oussoren E, van der Ploeg AT, Pijnappel W. Ready for repair? Gene editing enters the clinic for the treatment of human disease. Mol Ther Methods Clin Dev. 2020;18:532-57.

48. Grifman M, Trepel M, Speece P, Gilbert LB, Arap W, Pasqualini R, Weitzman MD. Incorporation of tumor-targeting peptides into recombinant adenoassociated virus capsids. Mol Ther J Am Soc Gene Ther. 2001;3(6):964-75.

49. Shen S, Berry GE, Castellanos Rivera RM, Cheung RY, Troupes AN, Brown SM, Kafri T, Asokan A. Functional analysis of the putative integrin recognition motif on adeno-associated virus 9. J Biol Chem. 2015;290(3):1496-504.

50. Reul J, Frisch J, Engeland CE, Thalheimer FB, Hartmann J, Ungerechts G, Buchholz CJ.Tumor-specific delivery of immune checkpoint inhibitors by engineered AAV vectors. Front oncol. 2019;9:52.

51. Lee SH, Kim YS, Nah SK, Kim HJ, Park HY, Yang JY, Park K, Park TK. Transduction patterns of adeno-associated viral vectors in a laser-induced choroidal neovascularization mouse model. Mol Ther Methods Clin Dev. 2018:9:90-8.

52. Cheng B, Ling C, Dai Y, Lu Y, Glushakova LG, Gee SW, McGoogan KE, Aslanidi GV, Park M, Stacpoole PW, et al. Development of optimized AAV3 serotype vectors: mechanism of high-efficiency transduction of human liver cancer cells. Gene Ther. 2012;19(4):375-84

53. Zolotukhin I, Luo D, Gorbatyuk O, Hoffman B, Warrington K Jr, Herzog $R$, Harrison J, Cao O. improved adeno-associated viral gene transfer to murine glioma. J Genet Syndr Gene Ther. 2013;4(133):12815.

54. Ruan H, Su H, Hu L, Lamborn KR, Kan YW, Deen DF. A hypoxia-regulated adeno-associated virus vector for cancer-specific gene therapy. Neoplasia (New York, NY). 2001;3(3):255-63.

55. Zhong X, Zhao H, Liang S, Zhou D, Zhang W, Yuan L. Gene delivery of apoptin-derived peptide using an adeno-associated virus vector inhibits glioma and prolongs animal survival. Biochem Biophys Res Commun. 2017:482(3):506-13.

56. Hammond SL, Leek AN, Richman EH, Tjalkens RB. Cellular selectivity of AAV serotypes for gene delivery in neurons and astrocytes by neonatal intracerebroventricular injection. PLoS ONE. 2017;12(12):e0188830.

57 Silva-Pinheiro P, Cerutti R, Luna-Sanchez M, Zeviani M, Viscomi C. A Single intravenous injection of AAV-PHP.B-hNDUFS4 ameliorates the phenotype of Ndufs4 (-/-) mice. Mol Ther Methods Clin Dev. 2020;17:1071-8.

58. Park K, Kim WJ, Cho YH, Lee YI, Lee H, Jeong S, Cho ES, Chang SI, Moon SK, Kang BS, et al. Cancer gene therapy using adeno-associated virus vectors. Front Biosci J Virtual Library. 2008;13:2653-9.

59. Hingtgen S, Ren X, Terwilliger E, Classon M, Weissleder R, Shah K. Targeting multiple pathways in gliomas with stem cell and viral delivered S-TRAIL and Temozolomide. Mol Cancer Ther. 2008;7(11):3575-85.

60. Chow RD, Guzman CD, Wang G, Schmidt F, Youngblood MW, Ye L, Errami $Y$, Dong MB, Martinez MA, Zhang S, et al. AAV-mediated direct in vivo CRISPR screen identifies functional suppressors in glioblastoma. Nat Neurosci. 2017;20(10):1329-41.

61. Ma HI, Hueng DY, Shui HA, Han JM, Wang CH, Lai YH, Cheng SY, Xiao X, Chen MT, Yang YP. Intratumoral decorin gene delivery by AAV vector inhibits brain glioblastomas and prolongs survival of animals by inducing cell differentiation. Int J Mol Sci. 2014;15(3):4393-414.

62. Mizuno M, Yoshida J, Colosi P, Kurtzman G. Adeno-associated virus vector containing the herpes simplex virus thymidine kinase gene causes complete regression of intracerebrally implanted human gliomas in mice, in conjunction with ganciclovir administration. Jpn J Cancer Res Gann. 1998;89(1):76-80.

63. Yoshida J, Mizuno M, Nakahara N, Colosi P. Antitumor effect of an adenoassociated virus vector containing the human interferon-beta gene on experimental intracranial human glioma. Jpn J Cancer Res Gann. 2002;93(2):223-8.

64. Hicks MJ, Funato K, Wang L, Aronowitz E, Dyke JP, Ballon DJ, Havlicek DF, Frenk EZ, De BP, Chiuchiolo MJ, et al. Genetic modification of neurons to express bevacizumab for local anti-angiogenesis treatment of glioblastoma. Cancer Gene Ther. 2015;22(1):1-8.

65. Yanamandra N, Kondraganti S, Gondi CS, Gujrati M, Olivero WC, Dinh DH, Rao JS. Recombinant adeno-associated virus (rAAV) expressing TFPI-2 inhibits invasion, angiogenesis and tumor growth in a human glioblastoma cell line. Int J Cancer. 2005;115(6):998-1005.

66. Ng SS, Gao Y, Chau DH, Li GH, Lai LH, Huang PT, Huang CF, Huang JJ, Chen $Y C$, Kung HF, et al. A novel glioblastoma cancer gene therapy using AAVmediated long-term expression of human TERT C-terminal polypeptide. Cancer Gene Ther. 2007;14(6):561-72.

67. Crommentuijn MH, Maguire CA, Niers JM, Vandertop WP, Badr CE, Würdinger T, Tannous BA. Intracranial AAV-sTRAIL combined with lanatoside $C$ prolongs survival in an orthotopic xenograft mouse model of invasive glioblastoma. Mol Oncol. 2016;10(4):625-34.

68. Bhere D, Tamura K, Wakimoto H, Choi SH, Purow B, Debatisse J, Shah K. microRNA-7 upregulates death receptor 5 and primes resistant brain tumors to caspase-mediated apoptosis. Neuro-oncol. 2018;20(2):215-24.

69. Ma HI, Guo P, Li J, Lin SZ, Chiang YH, Xiao X, Cheng SY. Suppression of intracranial human glioma growth after intramuscular administration of an adeno-associated viral vector expressing angiostatin. Can Res. 2002;62(3):756-63.

70. Tabatabai G, Weller M. Glioblastoma stem cells. Cell Tissue Res. 2011;343(3):459-65.

71. Brandes AA, Tosoni A, Franceschi E, Reni M, Gatta G, Vecht C. Glioblastoma in adults. Crit Rev Oncol Hematol. 2008;67(2):139-52.

72 Kim HY, Lee DK, Chung BR, Kim HV, Kim Y. Intracerebroventricular injection of amyloid- $\beta$ peptides in normal mice to acutely induce alzheimerlike cognitive deficits. J Vis Exp JoVE. 2016;109:e53308.

73. Hong H, Cui ZZ, Zhu L, Fu SP, Rossi M, Cui YH, Zhu BM. Central IGF1 improves glucose tolerance and insulin sensitivity in mice. Nutr Diabetes. 2017;7(12):2

74. Delenclos M, Faroqi AH, Yue M, Kurti A, Castanedes-Casey M, Rousseau L, Phillips V, Dickson DW, Fryer JD, McLean PJ. Neonatal AAV delivery of alpha-synuclein induces pathology in the adult mouse brain. Acta Neuropathol Commun. 2017:5(1):51.

75. Yang B, Li S, Wang H, Guo Y, Gessler DJ, Cao C, Su Q, Kramer J, Zhong L, Ahmed SS, et al. Global CNS transduction of adult mice by intravenously delivered rAAVrh.8 and rAAVrh.10 and nonhuman primates by rAAVrh.10. Mol Ther J Am Soc Gene Ther. 2014;22(7):1299-309.

76. Bourdenx M, Dutheil N, Bezard E, Dehay B. Systemic gene delivery to the central nervous system using Adeno-associated virus. Front Mol Neurosci. 2014;7:50.

77. Deverman BE, Pravdo PL, Simpson BP, Kumar SR, Chan KY, Banerjee A, Wu WL, Yang B, Huber N, Pasca SP, et al. Cre-dependent selection yields AAV variants for widespread gene transfer to the adult brain. Nat Biotechnol. 2016;34(2):204-9.

78. Chan KY, Jang MJ, Yoo BB, Greenbaum A, Ravi N, Wu WL, Sánchez-Guardado L, Lois C, Mazmanian SK, Deverman BE, et al. Engineered AAVs for efficient noninvasive gene delivery to the central and peripheral nervous systems. Nat Neurosci. 2017;20(8):1172-9.

79. Crommentuijn MH, Kantar R, Noske DP, Vandertop WP, Badr CE, Würdinger T, Maguire CA, Tannous BA. Systemically administered AAV9-sTRAIL combats invasive glioblastoma in a patient-derived orthotopic xenograft model. Mol Ther Oncolyt. 2016;3:16017.

80. GuhaSarkar D, Su Q, Gao G, Sena-Esteves M. Systemic AAV9-IFNB gene delivery treats highly invasive glioblastoma. Neuro-oncol. 2016;18(11):1508-18.

81. Rincon MY, de Vin F, Duqué SI, Fripont S, Castaldo SA, Bouhuijzen-Wenger J. Holt MG. Widespread transduction of astrocytes and neurons in the mouse central nervous system after systemic delivery of a self-complementary AAV-PHPB vector. Gene Ther. 2018;25(2):83-92.

82. Yi H, Zhang Q, Brooks ED, Yang C, Thurberg BL, Kishnani PS, Sun B. Systemic correction of murine glycogen storage disease type IV by an AAV-mediated gene therapy. Hum Gene Ther. 2017;28(3):286-94.

83. Fioravanzo A, Simbolo M, Giampiccolo D, Damante R, Pinna G, Scarpa A, Barresi V. Glioblastoma with tumor-to-tumor metastasis from lung adenocarcinoma. Neuropathology. 2019;39(6):474-8.

84. Kotterman MA, Yin L, Strazzeri JM, Flannery JG, Merigan WH, Schaffer DV. Antibody neutralization poses a barrier to intravitreal adenoassociated viral vector gene delivery to non-human primates. Gene Ther. 2015;22(2):116-26.

85. Zhang S, Hu ZW, Luo HY, Mao CY, Tang MB, Li YS, Song B, Wang YH, Zhang ZX, Zhang QM, et al. AAV/BBB-Mediated Gene Transfer of CHIP attenuates brain injury following experimental intracerebral hemorrhage. Transl Stroke Res. 2020;11(2):296-309. 
86. Gray SJ, Blake BL, Criswell HE, Nicolson SC, Samulski RJ, McCown TJ, Li W. Directed evolution of a novel adeno-associated virus (AAV) vector that crosses the seizure-compromised blood-brain barrier (BBB). Mol Ther J Am Soc Gene Ther. 2010;18(3):570-8.

87. Wang D, Tai PWL, Gao G. Adeno-associated virus vector as a platform for gene therapy delivery. Nat Rev Drug Discovery. 2019;18(5):358-78.

88. Chen C, Zuo W, Yang P, Zhang Y. Anti-PD-1, anti-VEGF, and temozolomide therapy in a patient with recurrent glioblastoma: a case report. J Int Med Res. 2020;48(9):300060520951395

89. Terzi D, Zachariou V. Adeno-associated virus-mediated gene delivery approaches for the treatment of CNS disorders. Biotechnol J. 2008;3(12):1555-63.

90. Keppeler D, Merino RM, Lopez de la Morena D, Bali B, Huet AT, Gehrt A, Wrobel C, Subramanian S, Dombrowski T, Wolf F, et al. Ultrafast optogenetic stimulation of the auditory pathway by targeting-optimized Chronos. EMBO J. 2018;37(24):e99649.

91. Xie J, Xie Q, Zhang H, Ameres SL, Hung JH, Su Q, He R, Mu X, Seher Ahmed S, Park S, et al. MicroRNA-regulated, systemically delivered rAAV9: a step closer to CNS-restricted transgene expression. Mol Ther J Am Soc Gene Ther. 2011;19(3):526-35.

92. Vagner T, Dvorzhak A, Wójtowicz AM, Harms C, Grantyn R. Systemic application of AAV vectors targeting GFAP-expressing astrocytes in Z-Q175-KI Huntington's disease mice. Mol Cell Neurosci. 2016;77:76-86.

\section{Publisher's note}

Springer Nature remains neutral with regard to jurisdictional claims in published maps and institutional affiliations.
Ready to submit your research? Choose BMC and benefit from:

- fast, convenient online submission

- thorough peer review by experienced researchers in your field

- rapid publication on acceptance

- support for research data, including large and complex data types

- gold Open Access which fosters wider collaboration and increased citations

- maximum visibility for your research: over 100M website views per year

At BMC, research is always in progress.

Learn more biomedcentral.com/submissions 